\title{
An Application of DMAIC Methodology for Increasing the Yarn Quality in Textile Industry
}

\author{
Neha Gupta \\ (Mechanical Department, Integral University, India)
}

\begin{abstract}
This article presents a quality improvement study applied at a yarn manufacturing company based on six sigma methodologies. More specifically, the DMAIC (Define, Measure, Analyze, Improve, and Control) project management-methodology \& various tools are utilized to streamline processes \& enhance productivity. Defects rate of textile product in the yarn manufacturing process is so important in industry point of view. It plays a very important rate for the improvement of yield \& financial conditions of any company. Actually defects rate causes a direct effect on the profit margin of the product \& decrease the quality cost during the manufacturing of the product. By checking \& inspection of defects of product at different point in production where more defects are likely to happen. A thousand defects opportunities create in the final package of yarn. That's why it is decided to do work \& implement DMAIC methodology in winding departments where the final package of yarn is make.
\end{abstract}

Keywords - Six Sigma; DMAIC; Lean manufacturing; Yarn manufacturing.

\section{INTRODUCTION AND BACKGROUND}

Organizations look for ways to improve their production and management processes in order to remain competitive in the market. This calls for ways to reduce production cost, enhance productivity and improve product quality. Therefore, organizations must utilize all the available resources efficiently and effectively in order to cater their customers with high quality products at a low price. For these reasons, researchers all over the world proposed several improvement strategies and tools to satisfy organization's needs. Such initiatives include Total Quality Management, Quality Awards, Total Preventive Maintenance (TPM), Lean and Six Sigma. The lean concept, which was initially referred to as the Toyota Production system, concentrates on the flow of the entire processes rather than on the optimization of individual operations [13]. Womack (2002) specified the main components of lean management system as follows:

- Identify process value from the customer perspective.

- Identify the value stream for each product and eliminate all types of wastes currently imbedded within the production process.

- Try to develop a continuous production process.

- Develop the pull management technique within the production lines.

- Manage toward perfection.

The main thing of Six Sigma is to taking the existing product, process and improves them in a better way. It is a very powerful approach to achieve the financial goals for the organization and improving the company's value by the following:

- Data driven

- Project based

- Disciplined and systematic

- Customers focused (internal \& external)

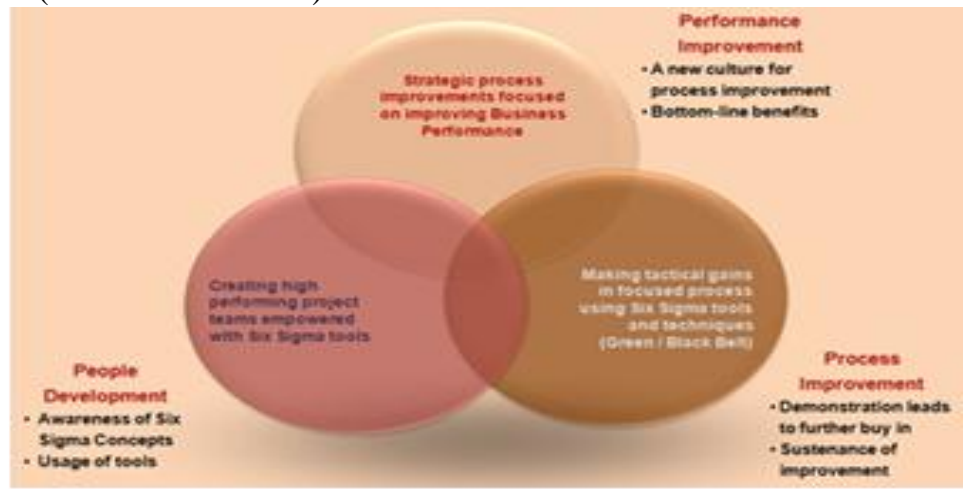

Fig. 1: Six Sigma Methodology for improvement 
Six Sigma, on the other hand, is a data driven methodology used to identify root causes for variations in a production processes in order to achieve organizational excellence. Six Sigma management strategies require process improvement through identifying problem, root causes, process redesign and reengineering, and process management. Six Sigma follows a model known as DMAIC (Define, Measure, Analyze, Improve, and Control). Therefore, Six Sigma starts by analyzing defects and lean initial focus is on customer, process flow, and waste identifications [23]. However, using one of these tools has limitations. Since lean eliminates the use of Six Sigma's DMAIC cycle as a management structure to define required process capabilities to be truly lean. On the other hand, Six Sigma eliminates defects but does not address how to optimize the process flow. Hence, applying both Six Sigma and Lean tools sets results in far better improvements than could be achieved with either one method alone [16].

DMAIC is a systematic six-sigma project management practice inspired by Deming's PDCA (Plan, Do, Check, and Act) Cycle. The process consists of the five phases called Define, Measure, Analyze, Improve and control.

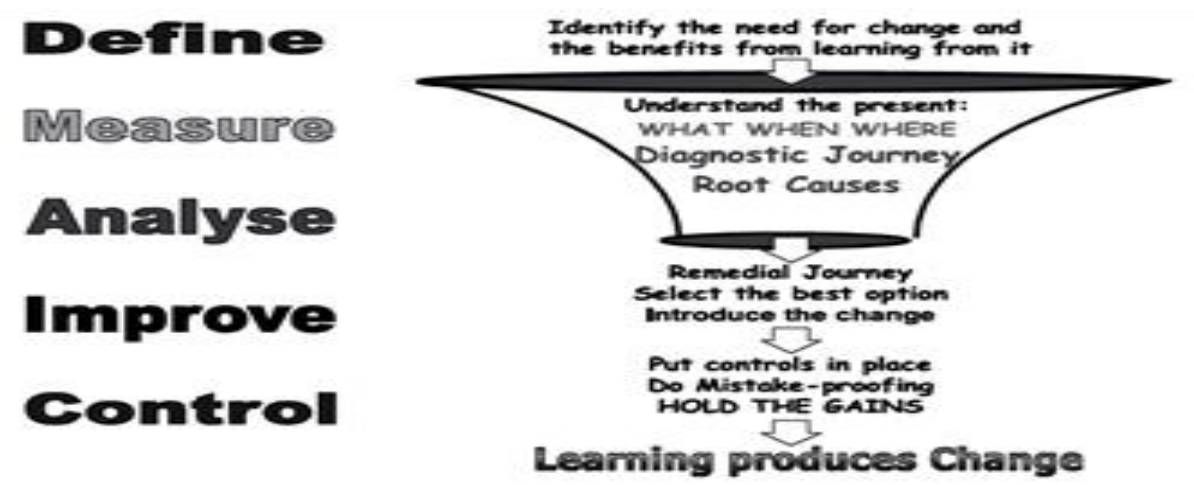

Fig. 2: Six Sigma Methodology DMAIC

The Define phase concentrates on forming the team, defining the project's goals, mapping the process, identifying customers, and identifying the high impact characteristics or the CTQs (Critical to Quality). The Measure phase consists of defining and executing a systematic data collection plan for the key measures (CTQs) for the targeted process. Data collected in the Measure phase are analyzed in the Analyze phase to identify the root causes behind the gap between the current performance and the goals identified in the first phase by defining the main type of wastes embedded within the production processes and the root causes for these wastes. The Improve phase focuses on identifying expected solutions, suggest set of alternative solutions to enhance performance, and implement some of these solutions according to the available budget and the expected cost for each alternative. The Control phase concentrates on creating and implementing monitoring and response plans for sustaining improvements, spread out the outcome and the methodology for the whole organization, insure the establishment of a new culture within the organization. Moreover, operating standards and procedures are documented and published in the Control phase.

Lean and Six Sigma have been implemented successfully in the manufacturing and service sectors to optimize different performance measures. Both lean and Six Sigma methodologies have proven over that last twenty years that it is possible to achieve dramatic improvements in cost, quality, and production time by focusing on process performance. Linderman et al. (2003) pointed out that Six Sigma could be implemented to the processes of producing manufacturing goods, business trade, executive management, and services. Recent research papers include improving operational safety [5], reducing amount of waste [8], improving quality for surveillance cameras to diminish related excess costs [10], enhancing the assembly efficiency of military products [4], increasing customer loyalty in the banking sector for Bank of America and Citigroup [21, 22], reducing patients' waiting time and length of stay $[3,17,29]$, reducing length of stay for Ophthalmology Day Case Surgery [16], reducing lead-time [1], enhancing staff satisfaction [7], reducing clinical errors [20], process improvement for both the radiology department and medication administration process [15], and process design of compressor-housing machining process [25]. Others include [2, 6, 11, 12, 18, 19, 24, 26, 28, 29].

As a summary, both lean and six sigma methodologies have proven over that last twenty years that it is possible to achieve dramatic improvements in cost, quality, and production time by focusing on process performance. In this paper, a customized lean Six Sigma methodology is deployed at a local paper manufacturing company to increase production rate, minimize waste and increase Overall Equipment Effectiveness (OEE). The two tools have been used as complementary to each other, wherein DMAIC's roadmap has been used as a general framework for process improvement and lean tools have been embedded within these phases. Furthermore, the research focuses on employee involvement and motivation that are imperative to advance a new culture [9]. 
Sigma value increases the process performance in a better way. Another way of measure the process capability and performance by the statistical measurements like Cp, Cpk, Pp and Ppk. The Six Sigma means a $3.4 \%$ defects part per million or yield of $99.9997 \%$ (perfect parts). Following is the table 1 of comparison of different Sigma values at different defects part per million and capability of process here [31].

Table 1. The Comparison of Different Sigma Values

\begin{tabular}{|c|c|c|c|}
\hline SIGMA & DPMO & COPQ & CAPABILITY \\
\hline 6 Sigma & 3.4 & < $10 \%$ of sales & World Class \\
\hline 5 Sigma & 230 & 10 to $15 \%$ of sales & \\
\hline 4 Sigma & 6200 & 15 to $20 \%$ of sales & Industry Average \\
\hline 3 Sigma & 67000 & 20 to $30 \%$ of sales & \\
\hline 2 Sigma & 310,000 & 30 to $40 \%$ of sales & Noncompetitive \\
\hline 1 Sigma & & & \\
\hline
\end{tabular}

\subsection{Blow room Process}

\section{BRIEF INTRODUCTION OF YARN MNUFACTURING DEPARTMENTS}

Blow room is the initial stage in spinning process. The name blow room is given because of the "air flow" And all process is done in blow room because of air flow. Blow room is consisting of different machines to carry out the objectives of blow room. In blow room the tuft size of cotton becomes smaller and smaller. Mixing of cotton is done separately as well as in blow room. Compressed layer of bale is also open in blow room with the help of machine.

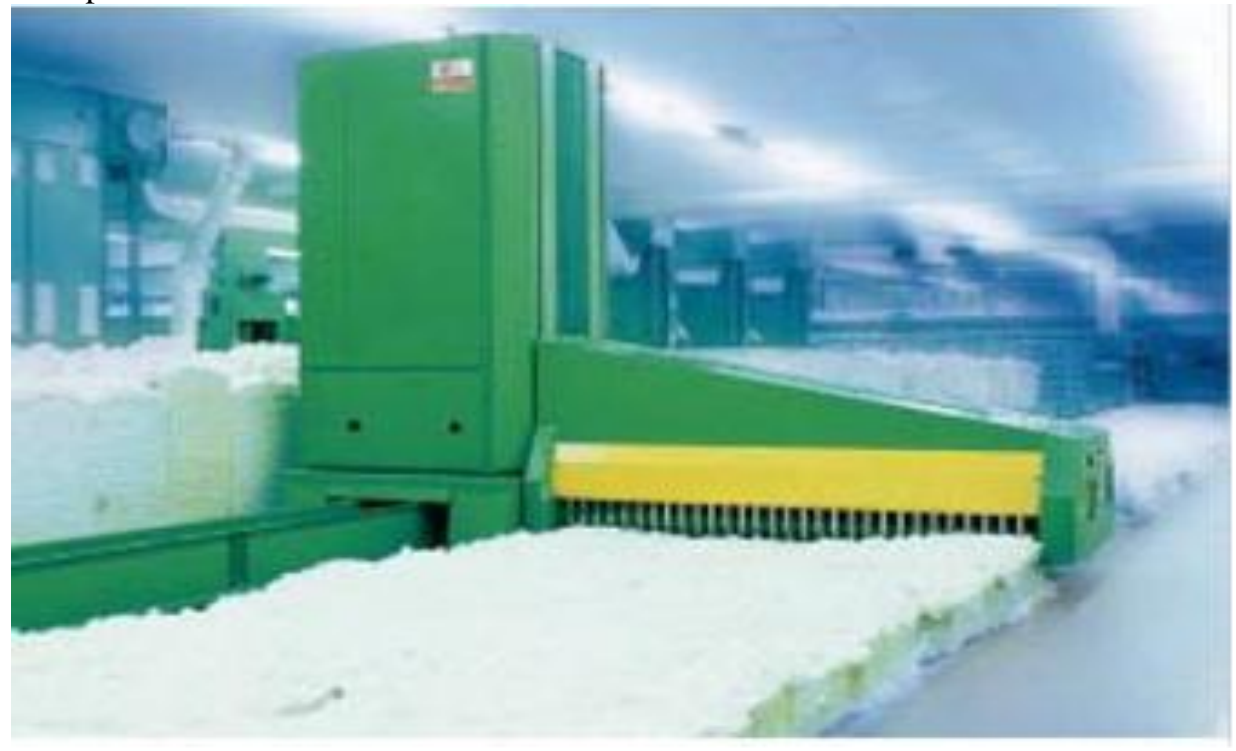

Fig. 3: Blow Room Department

\subsection{Carding Process}

Carding process is very important role in spinning mill. It helps us both way to open the tuft into a single fiber and to remove the impurities and neps. Textile experts are convinced for the accuracy of following statement.

"The card is the heart of spinning mill" and "well carded is well spun" (Vijykumar, 2007). [34]

Card feeding is done by two ways. One is manually and other is through chute feed system. In manual case the lap which is produced in blow room and it is feed to the card. In chute feed the material is feed through air flow system to card machine. It is important to say that lower the feed variation better is the carding quality. Lower the feed variation then draft variation will also be less. Then yarn quality will be consistent. If the card is having auto leveler then nominal draft should be selected properly. In some circumstances card also act as a cleaner and remove a certain amount of short fiber. Approximately $90 \%$ cleaning efficiency is achieved with the help of carding machine. [35] 


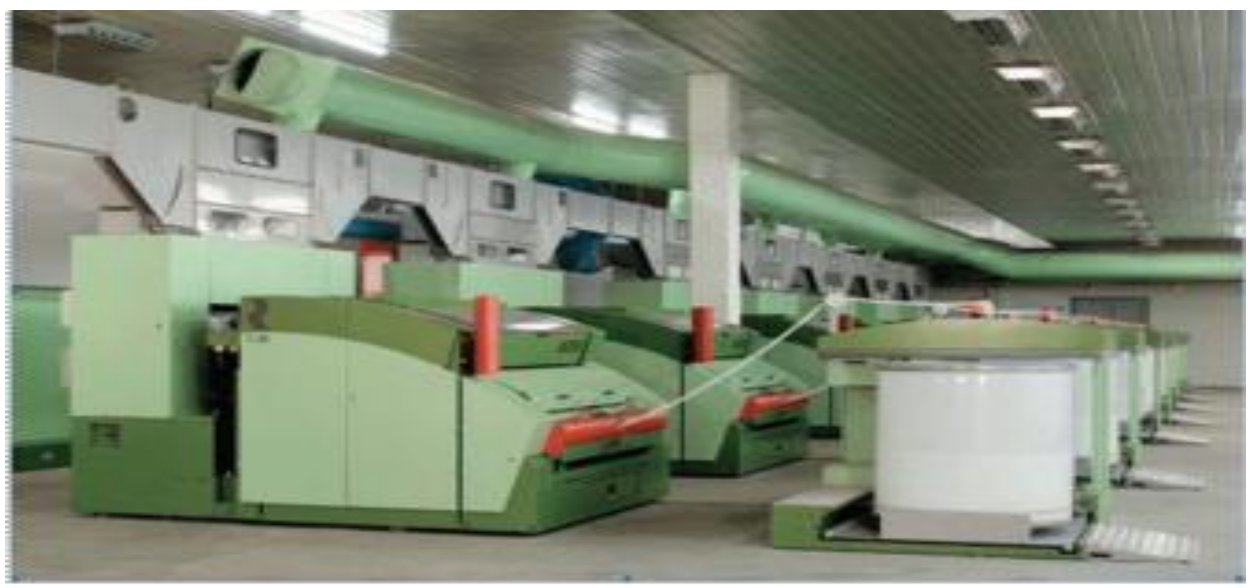

Fig. 4: Carding Machine

\subsection{Drawing frame Process}

Draw frame is simple and cheap machine. In spinning regarding to quality point of view it play very important role .If its setting is not done properly then it affects yarn strength and elongation. For improving quality draw frame is final process in the spinning mill. It effects on quality especially on evenness of sliver. In the spinning process there are chances of elimination of errors in draw frame machine. Draw frame play very important role for the quality of yarn. Without it participation quality can never be improved. [4]Drafting arrangement is the heart of the draw frame. Drafting arrangement should be simple, stable design, should have ability to produce high quality product. It should have high fiber control. Auto leveler is also used to adjust and to improve the linear density of the sliver. Without auto leveler it is very difficult to improve the quality of the draw frame sliver. [36]

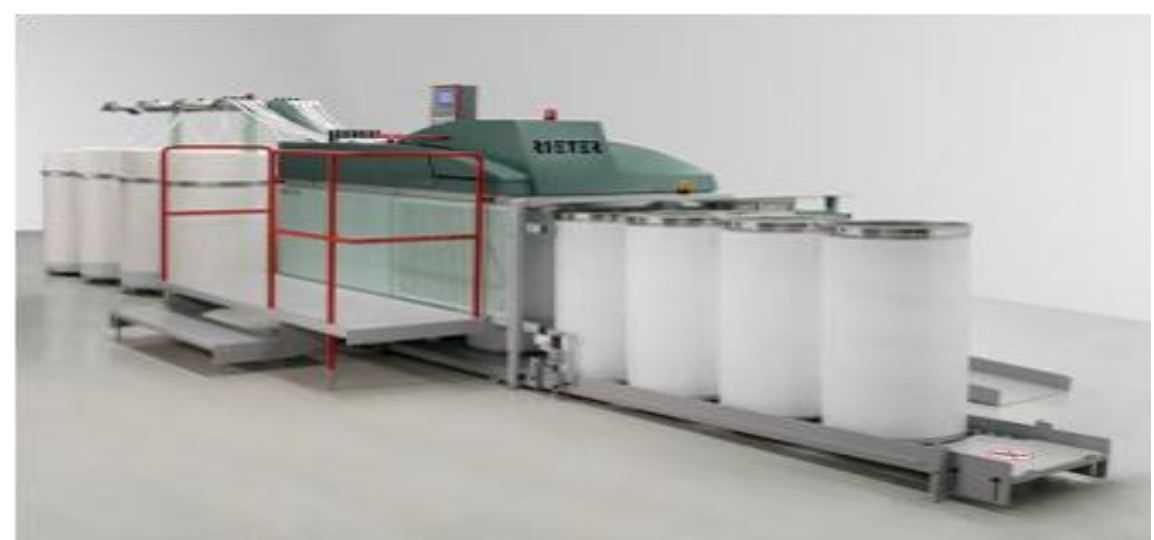

Fig. 5: Drawing Frame Department

\subsection{Combing process}

For getting high quality of yarn, one extra process is introduced which is called combing process. Combing is an operation in which dirt and short fibers are removed from sliver lap by following ways.

- In specially designed jaws, a narrow lap of fiber is firmly gripped across its width.

- Closely spaced needles are passed through the fiber projecting from jaws.

Short fiber which we remove is called comber noil. The comber noil can be recycled in the production of carded yarn. Yarn which is get from comber sliver is called comber yarn. Carded sliver are combine into comber lap in a single continuous process stage. Flat sheet of fiber which is get from comber lap is fed into the comber in an intermediate.

There are different ways by which value of combing is used in the manufacturing of cotton. By spinning point of view combing process makes more uniformity in the yarn. Strength of yarn is also high because in combing process short fiber are removed and only fiber having good strength remains. So it play very important role for increasing the yarn strength. Because of straightened condition of fibers combing makes possible spinning smoother and more lustrous yarn. In combing process length of fiber are strong so it need less twist produced then carded yarn [53]. 


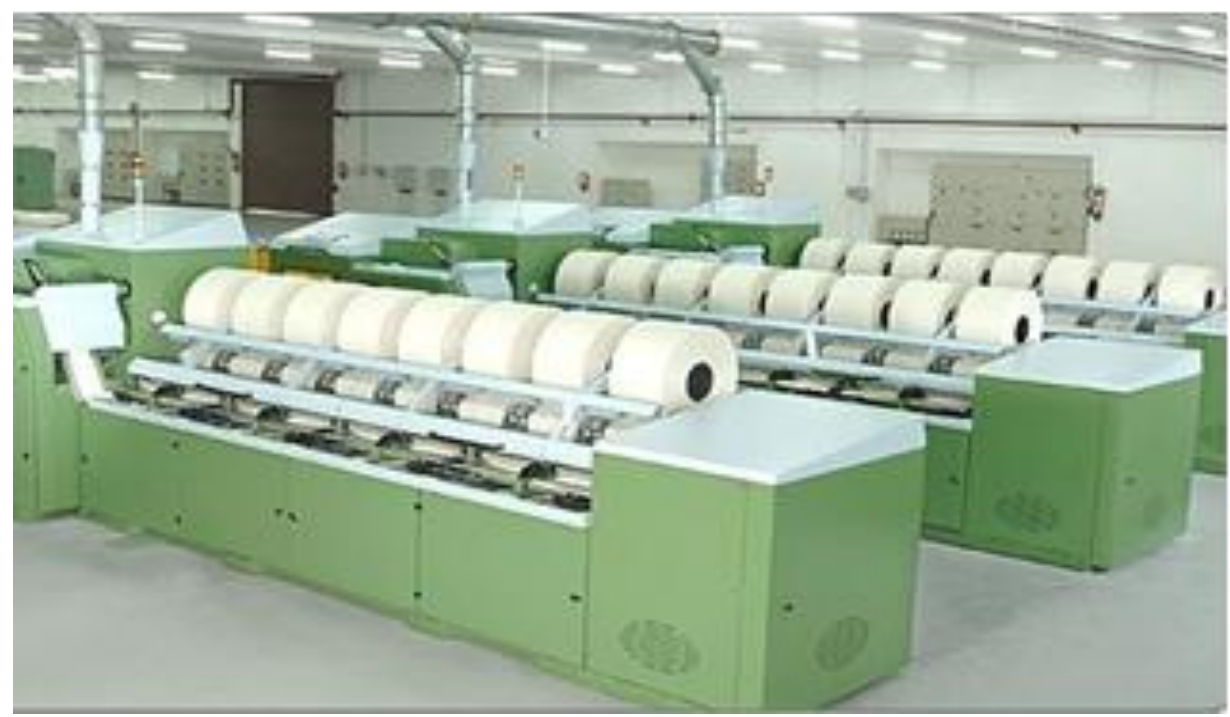

Fig. 6: Combing Department

\subsection{Roving frame}

It is an intermediate process in which fibers are converted into low twist lea called roving. The sliver which is taken from draw frame is thicker so it is not suitable for manufacturing of yarn. Its purpose is to prepare input package for next process. This package is to prepare on a small compact package called bobbins. Roving machine is complicated, liable to fault, causes defect adds to the production costs and deliver the product. In this winding operation that makes us roving frame complex. There are two main basic reasons for using roving frame.

- The roving sliver is thick and untwisted. Because of it hairiness and fly is created. So draft is needed to reduce the linear density of sliver. The ring drafting arrangement is not capable that it may process the roving sliver to make the yarn.

- Draw frame can represent the worst conceivable mode of transport and presentation of feed material to the ring spinning frame.

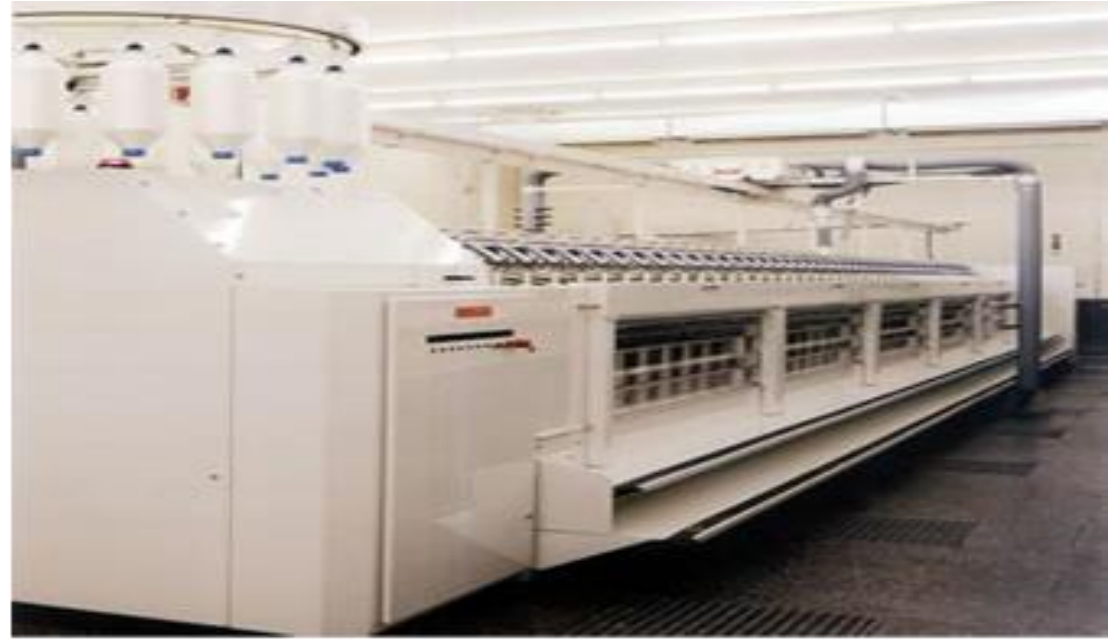

Fig. 7: Roving Machine

\subsection{Ring Spinning Process}

Ring Spinning machine is used in textile industry to twist the staple fibers into a yarn and wind on a bobbin for storage and also input for the winding section for more precise the yarn to minimize the defects of end yarn. Ring machine is very important due to yarn quality. Ring Spinning is the most costly step to convert fibers into yarn and approximately $85 \%$ yarn produced in ring spinning frame all over the world. It is made to draft the roving into a desired count and impart the desired twist to produce the strength in the yarn. If twist is increased, yarn strength is also increased at optimum limit. 


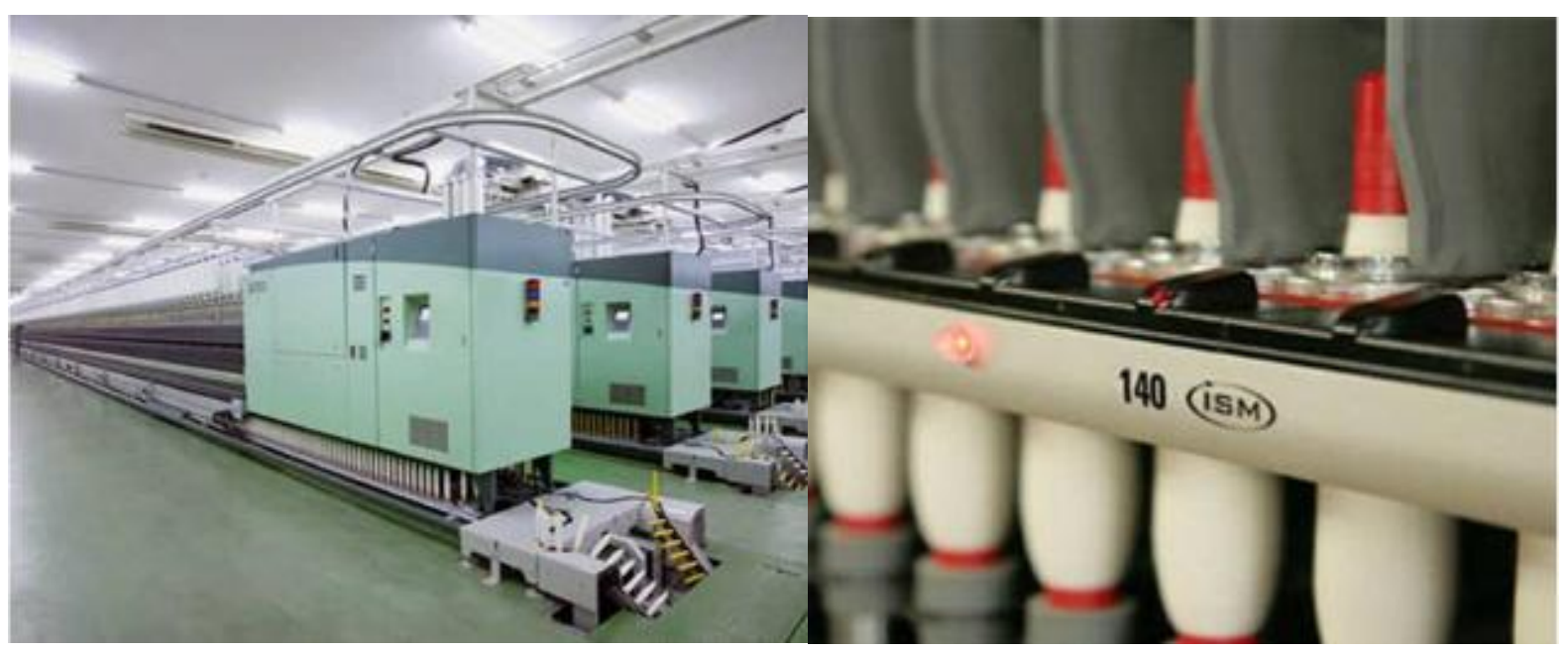

Fig. 8: Ring Spinning Machine

\subsection{Winding Section}

It is the last section of yarn manufacturing process where auto cone machines are installed and take an input material from ring spinning section as a yarn bobbin and give a yarn on paper cone after passing detecting instrument as a output. In winding section, there are lot of heads in auto cone machines use to wound the yarn from ring bobbin yarn to paper cone yarn. Now days, there are some companies to manufacturing these machines and Savio company is one of them which produce a fully automatic machine for spinning industries. In quality point of view, it is a very good machine and has also very low maintenance cost. Winding department plays an important role in the production and quality of yarn and causes direct effect on them. The yarn which made in ring section is not finish yarn and can't sell to customer. After making the yarn in ring process, auto cone section made it more even yarn by passing through the optical sensor which is installed in different heads of machine. The yarn which is obtained from winding section is able to sell the customers.

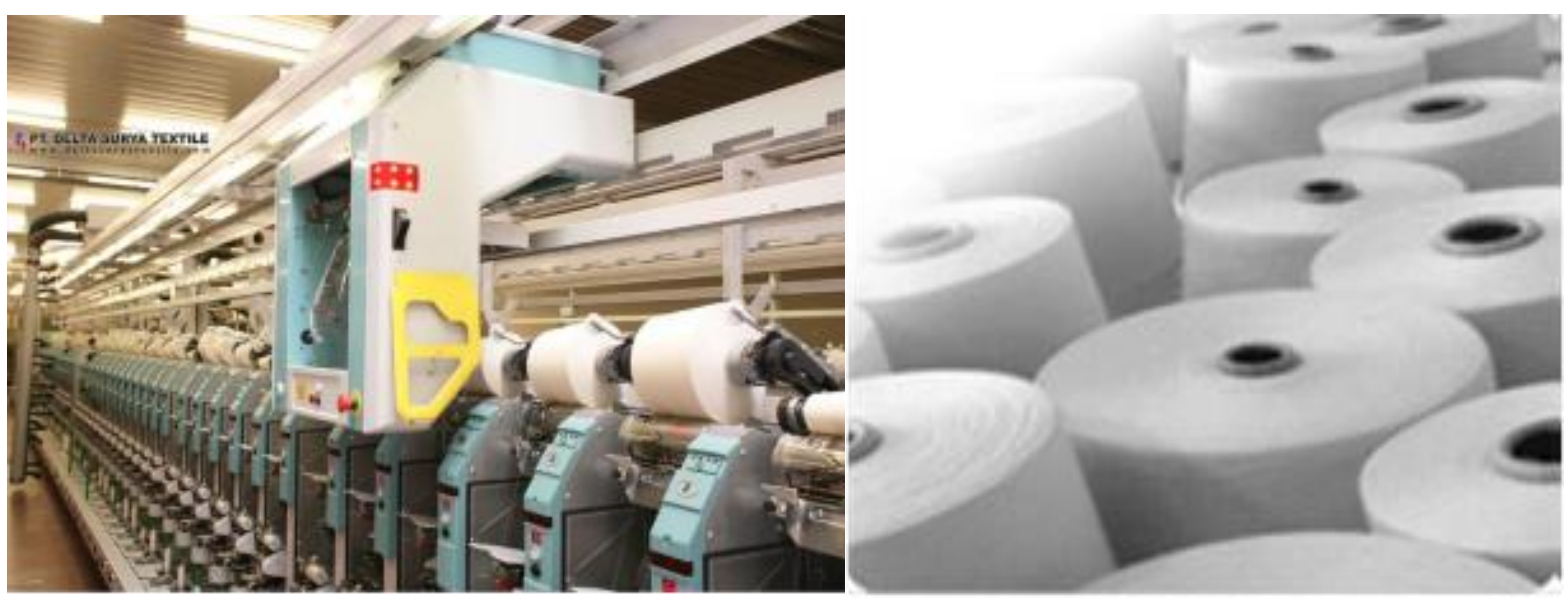

Fig. 9: Winding Machine

\section{Problem STATEMENT}

This paper is related to textile industry especially to Yarn manufacturing process. This paper identifies the different problems occurring during manufacturing of yarn in the last process (winding), DMAIC tool is applied by the practical examples which was applied in practical field. It is very complicated and important process and it's difficult to achieve the quality throughout the process.

The main reason is the raw material, which do not possess good properties such as maturity, degree of reflectance, impurity and fiber strength and shade variation from bale to bale. The main thing in this paper is to reduce the defects rate and also reduce fault opportunities in the final yarn, As in Six Sigma methodology, if we decrease the opportunities in the final product then we can increase the Sigma value which shows that the process improvement. We have also applied a basic tool of Six Sigma like DMAIC which highlighted the different phases of tool with respect to process behavior and importance in the manufacturing of yarn. Winding department where we have applied DMAIC tool is critical as compared to other departments in the process as it cause an increase defects rate percentage in the final product of yarn. 
In winding department, there is an Auto cone machine which winds the yarn on the cone and makes a final package for the end customers. It's better to implement DMAIC tool to eliminate or reduce the defects at the last section of the department. After this section, we can't improve the quality or reduce the defects in the final product.

\section{RESEARCH METHODOLOGY}

During production of different processes in the yarn manufacturing process, there are failures at many stages. All such failures are recorded in the manufacturing plant. It was observed that worst defects $\%$ is at winding stage. So it was decided to implement DMAIC tool in this process to eliminate a large variation in it. During this it was focused in all three departments such as Quality, Maintenance and Production. I followed all the standards which play important role for the satisfaction of the customer needs and expectations.

Maintenance play important role in every field. It play very important role regarding to quality. Because of proper maintenance, quality of product will be better. So it was focus on maintenance department as well. Winding section is a very critical department in yarn manufacturing process.

In this department there are a lot of chances of defects opportunities in the final yarn. It is the last section of manufacturing process where defects can be minimized or eliminated. After manufacturing of yarn from deferent departments in the preparatory process and ring department it is ready to make a shape into final cone form so that it can be shipped to customer for use. During winding process of yarn following objectives are met.

- Scanning and faults removing

Electric Scanners (uster) is used for checking and elimination of yarn faults during winding process. This process is called Usterization of yarn. Such faults are called scan-cuts.

- Splicing of broken or cut yarn

Auto splicing is done for broken yarn pieces to eliminate yarn knots and bad piecing.

- Bigger package

Conversion of yarn from small ring bobbins to bigger yarn cones of different international standard or as per requirement of customer.

During achieving above objectives or making of winding cones some faults are created during the process. These faults need to be controlled through monitoring and continuous study. Most of the winding faults are very dangerous for the next subsequent process which can be warping or knitting or doubling. We can face complains from customer of breakage of yarn during unwinding process.

The following subsections illustrate how the DMAIC cycle is used to increase the quality and reduce the defects rate in the yarn manufacturing company.

\subsection{Define Phase}

In this phase, define the process at different angles with the help of tools like Pareto chart, XY matrix and cause and effect diagram. First of all there is a comparison of rejection rate of different departments given below.

\subsubsection{Rate of Rejection of Departments}

Table 2. Comparison of Rejection Rate of Different Departments

\begin{tabular}{|c|c|c|c|c|c|}
\hline Area & Defects & Production & Defects \% & DPMO & $\begin{array}{c}\text { Sigma } \\
\text { level }\end{array}$ \\
\hline B Grade & 5303 & 4684800 & 0.11 & 1132 & 4.5 \\
\hline Final Inspection & 0 & 4684800 & 0.00 & 0 & 6 \\
\hline Packing & 1227 & 4684800 & 0.03 & 262 & 4.97 \\
\hline Doubling & 494 & 494700 & 0.10 & 999 & 4.59 \\
\hline Winding & $\mathbf{4 9 7 5 2}$ & $\mathbf{4 6 8 4 8 0 0}$ & $\mathbf{1 . 0 6}$ & $\mathbf{1 0 6 2 0}$ & $\mathbf{3 . 8 1}$ \\
\hline Ring & 4852 & 4684800 & 0.10 & 1036 & 4.58 \\
\hline Simplex & 14795 & 4684800 & 0.32 & 3158 & 4.54 \\
\hline Can \& Lap & 2660 & 4684800 & 0.06 & 568 & 4.76 \\
\hline
\end{tabular}




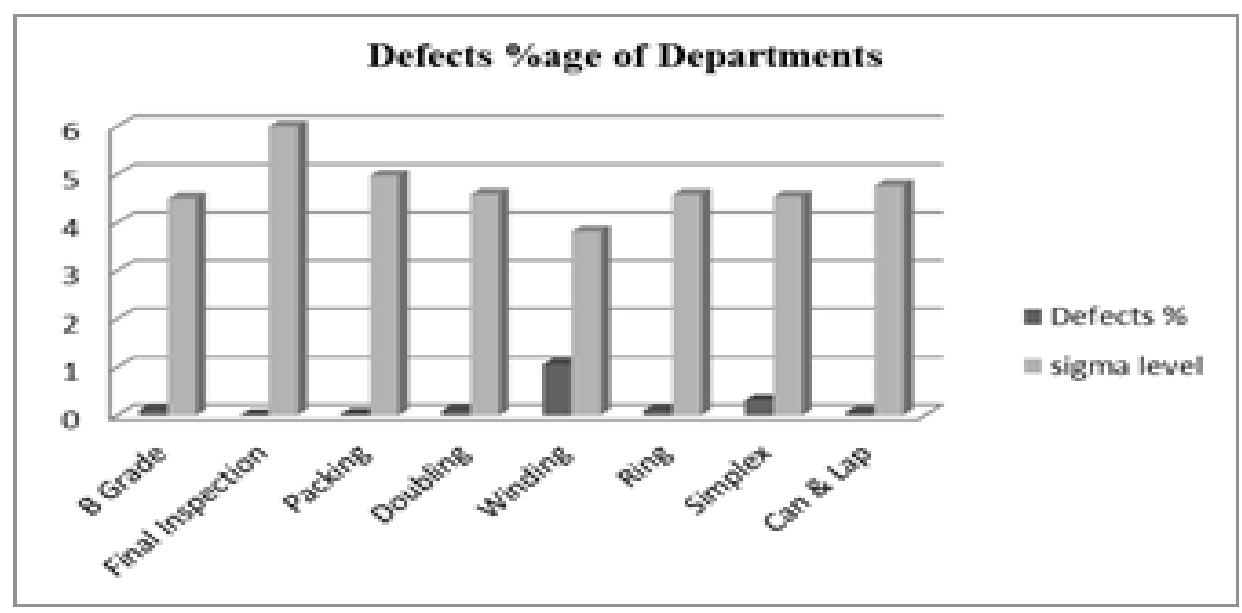

\begin{tabular}{|c|c|c|}
\hline & Defects\% & Sigma level \\
\hline B Grade & 0.11 & 4.5 \\
\hline Final Inspection & 0.00 & 6 \\
\hline Packing & 0.03 & 4.97 \\
\hline Doubling & 0.10 & 4.59 \\
\hline Winding & 1.06 & 3.81 \\
\hline Ring & 0.10 & 4.58 \\
\hline Simplex & 0.32 & 4.54 \\
\hline Can \& Lap & 0.06 & 4.76 \\
\hline
\end{tabular}

Fig. 10. Defects\% age of Departments

\subsubsection{SIPOC Diagram}

As it is decided to work and analysis the defects in winding section, following SIPOC diagram is used to understanding the clear relationship between customer and supplier relationship.

Table 3. SIPOC (SUPPLIER, INPUT, PROCESS, OUTPUT, CUSTOMER) Diagram

\begin{tabular}{|c|c|c|c|c|}
\hline Supplier & Input & Process & Output & Customer \\
\hline $\begin{array}{c}\text { Roving } \\
\text { Department }\end{array}$ & $\begin{array}{l}\text { Roving } \\
\text { Bobbin }\end{array}$ & Spinning & $\begin{array}{l}\text { Ring Yarn } \\
\text { Bobbin }\end{array}$ & $\begin{array}{c}\text { Preparatory of } \\
\text { Winding Machine }\end{array}$ \\
\hline $\begin{array}{c}\text { Preparatory of } \\
\text { Winding Machine }\end{array}$ & $\begin{array}{l}\text { Ring Yarn } \\
\text { Bobbin }\end{array}$ & End Finder & $\begin{array}{l}\text { Bobbin with end } \\
\text { at top }\end{array}$ & Winding Spindle \\
\hline Winding Spindle & $\begin{array}{l}\text { Bobbin With } \\
\text { end at top }\end{array}$ & Winding & Wound cone & Auto doffer \\
\hline Auto doffer & Wound cone & Auto doffing & Doffed Cone & Inspection Department \\
\hline $\begin{array}{c}\text { Inspection } \\
\text { Department }\end{array}$ & Doffed Cone & Inspection & Inspected Cone & Packing \\
\hline $\begin{array}{c}\text { Inspection } \\
\text { Department }\end{array}$ & $\begin{array}{l}\text { Inspected } \\
\text { Cone }\end{array}$ & Pallet Formation & Cone on Pallet & Packing \\
\hline Packing & Cone on Pallet & Steaming & Steamed Cone & Packing \\
\hline Packing & Steamed Cone & $\begin{array}{l}\text { Repacking \& } \\
\text { Inspection }\end{array}$ & $\begin{array}{c}\text { Packed Cone on } \\
\text { Pallet }\end{array}$ & $\begin{array}{l}\text { Packing and Quality } \\
\text { Control }\end{array}$ \\
\hline Packing & $\begin{array}{l}\text { Packed Cone } \\
\text { on Pallet }\end{array}$ & $\begin{array}{c}\text { Shrink } \\
\text { Wrapping }\end{array}$ & Packed Pallets & Logistic, Quality Control \\
\hline Logistic & Packed Pallets & Yarn Storage & Ready for & Marketing, Quality Control \\
\hline Logistic & Stored Yarn & Final Inspection & Pass Pallets & Marketing, Customer \\
\hline Logistic, Marketing & Pass Pallets & $\begin{array}{l}\text { Delivery to } \\
\text { customer }\end{array}$ & $\begin{array}{l}\text { Delivered } \\
\text { Pallets }\end{array}$ & Customer \\
\hline
\end{tabular}


4.1.3 Winding Defects

There are many defects which are produced in winding section and show them in bar graph here.

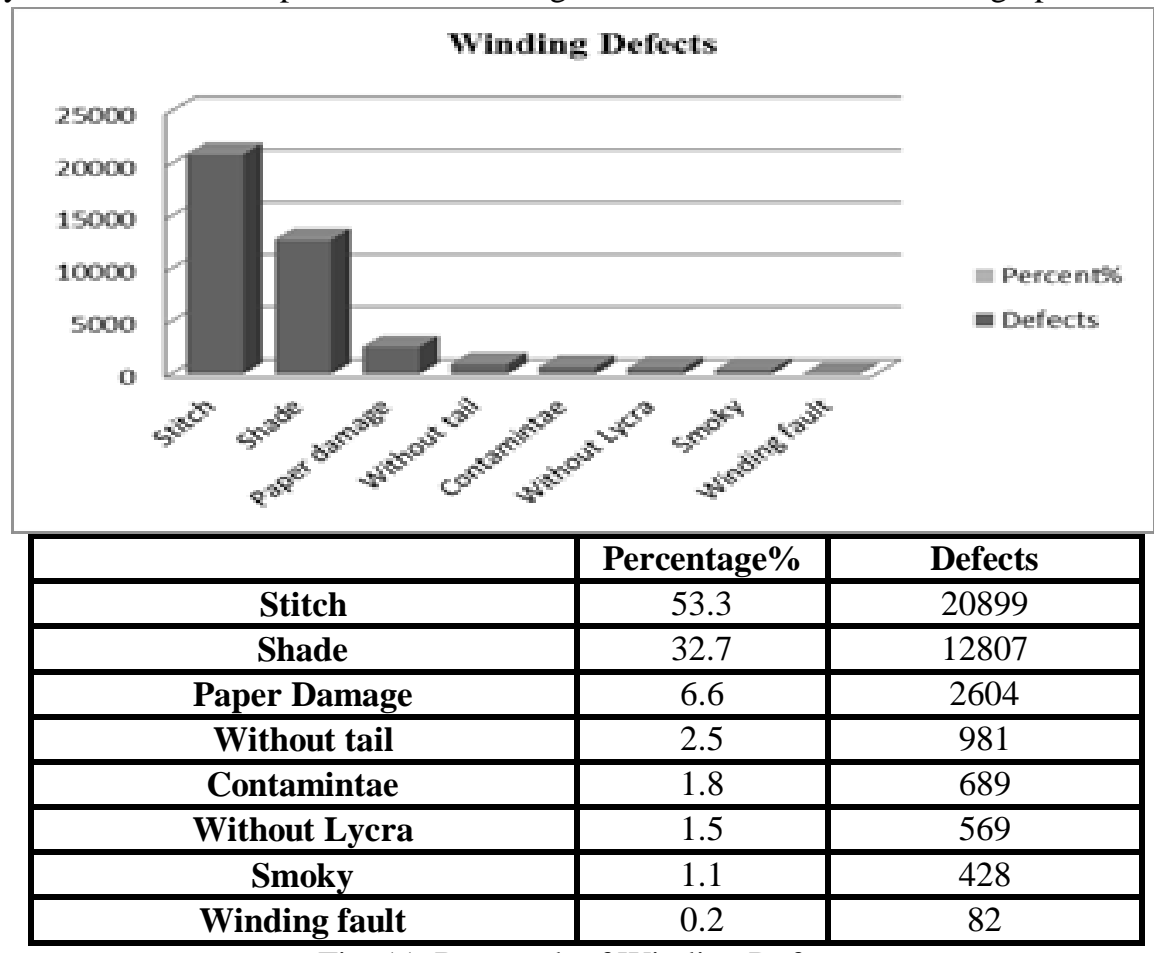

\subsection{Measure Phase}

Fig. 11. Bar graph of Winding Defects

To start the measurement phase a standard from has been designed and distributed to the DMAIC team, from contain the necessary information that should be gathered to be analyzed at the next phase, these information comprise from product type, raw materials type, machine parameters, type of wastes combined with general comments. Measure the performance of the process by collecting the data and also write down the importance of different critical defects regarding to customer value. In this phase there is different data analysis here

- Cause and Effect Analysis

- Data Collection Plan

- Measurement system analysis

4.2.1 Cause \& Effect Analysis

Rating Scale 1 9 (1 being lowest and 9 being highest)

\begin{tabular}{|c|c|c|c|c|c|c|c|c|c|c|c|}
\hline & 1 & 2 & 3 & 4 & 5 & 6 & 7 & 8 & \\
\hline \multicolumn{3}{|c|}{$\begin{array}{c}\text { Rating of Importance to } \\
\text { Customer }\end{array}$} & 10 & 6 & 6 & 1 & 8 & 8 & 9 & 7 & \\
\hline \multicolumn{3}{|c|}{ Key Process Outputs } & 0 & & & & & & & & \\
\hline & $\begin{array}{l}\text { Process } \\
\text { Step }\end{array}$ & $\begin{array}{c}\text { Process } \\
\text { Input }\end{array}$ & & & & & & & & & Total \\
\hline \multirow[t]{3}{*}{1} & $\begin{array}{l}\text { Winding } \\
\text { Machine }\end{array}$ & Guide & 9 & 9 & $\overline{1}$ & 3 & 3 & 3 & 3 & $\overline{1}$ & 235 \\
\hline & & Gas Kit & 9 & 9 & 1 & 1 & 1 & 3 & 3 & 1 & 217 \\
\hline & & Disk & 9 & 9 & 1 & 1 & 3 & 3 & 3 & 1 & 233 \\
\hline
\end{tabular}


An Application of DMAIC Methodology for Increasing the Yarn Quality in Textile Industry

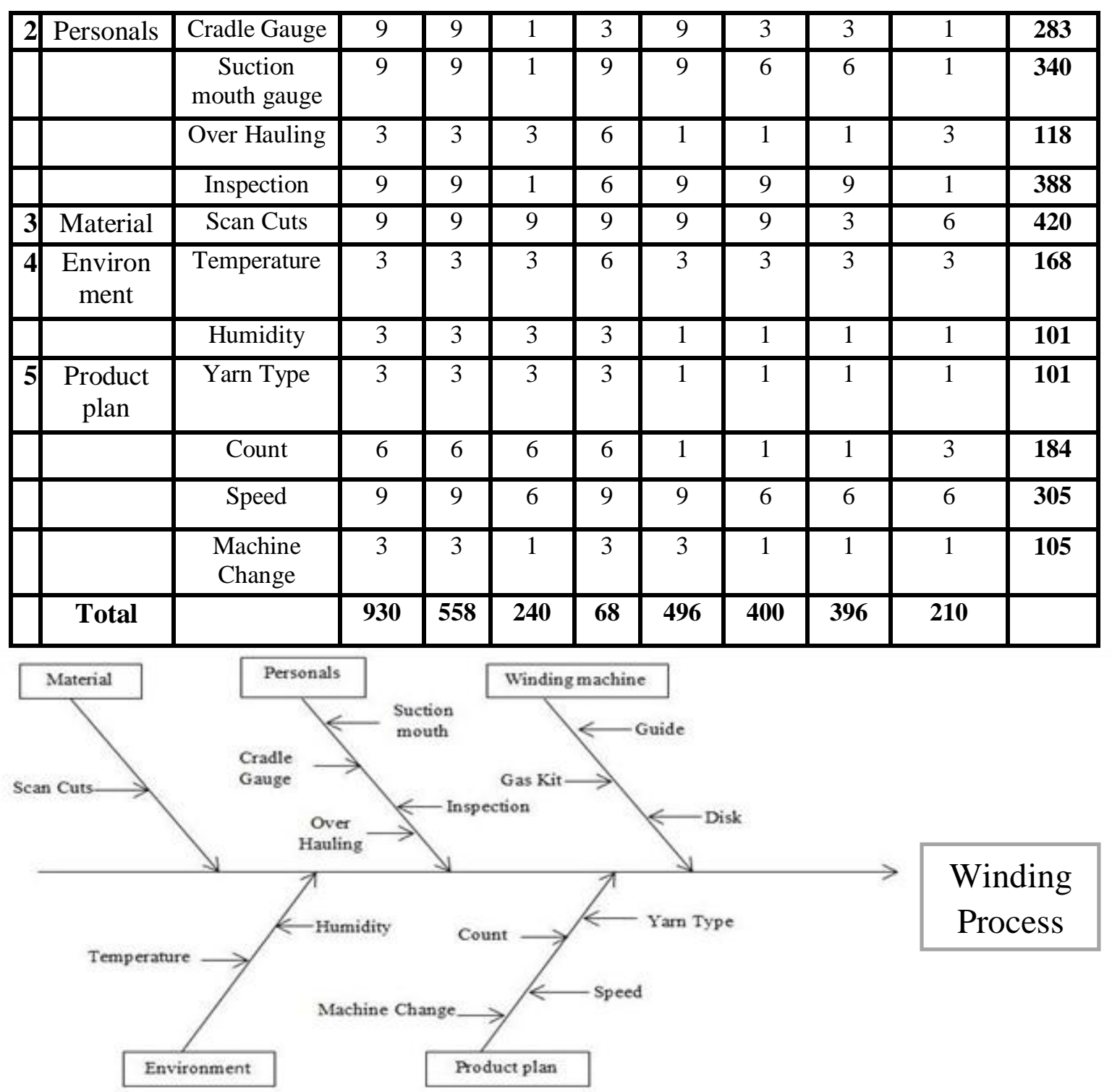

Fig.12. Cause \& Effect Diagram

\subsubsection{Data Collection Plan}

There is different way where the data collect of the yarn manufacturing process. Following are the different types of data which is collected from different source.

For identify the problem of cross stitch, there is data collected here.

- The system in a manufacturing plant is to collect a lot of data from department is already established.

- Date and month, Yarn type, Operator and his experience, yarn count, Shift, production, Machine type and machine number, our hauling, scan cuts, Speed of machine, Temperature and humidity.

- Responsibilities of person is shown in data to highlight the clear understanding regarding to process data and also take a data collection source like production and maintenance rejection report.

It is an especially design experiment to identify the variation in the measuring components. A measurement system analysis considers the following things related to the process.

- Selection of correct measurement system and approach.

- Capability and assessing the measuring device.

- Assessing of operators and procedures implement in a process.

- Calculating the uncertainty in the measurement.

\subsubsection{Measurement system analysis for Defective Yarn cones}

At winding section, inspection of yarn cone is done manually and conducts a MSA of attribute data.

Sample Selection-

Sample Size $=50$ cones 
Pass cones $=20$

Fail Cones $=20$

Borderline cones $=10$

Number of operators $=3$

Number of trials / operator $=2$

Overall \%age appraiser $=82 \%$

Overall \%age attribute $=76 \%$

- Appraiser \%age of this sample selection shows that it should be needed to retrain the inspectors to reduce the error.

- Attribute \%age of this sample shows that it should be needed to improve the existing system and redefine the defects parameters of winding section.

\subsection{Analysis Phase}

The analysis phase deals with identifying the root causes of the process whether it can be improved or redesigned the process. To understand the defects stitch following studies \& charts were produced to analyze this problem from different angles.

\subsubsection{Effect of over hauling, product change and shift on Stitch defect}

Data shows that Evening shift has more defects as compared to morning and night shift. The night shift has minimum defects during manufacturing process.

By deeply analyzing this problem, whenever change the product at machine or run the machine after overhauling changes of Stitch defects increases in first shift. Up till second shift things get normalized.

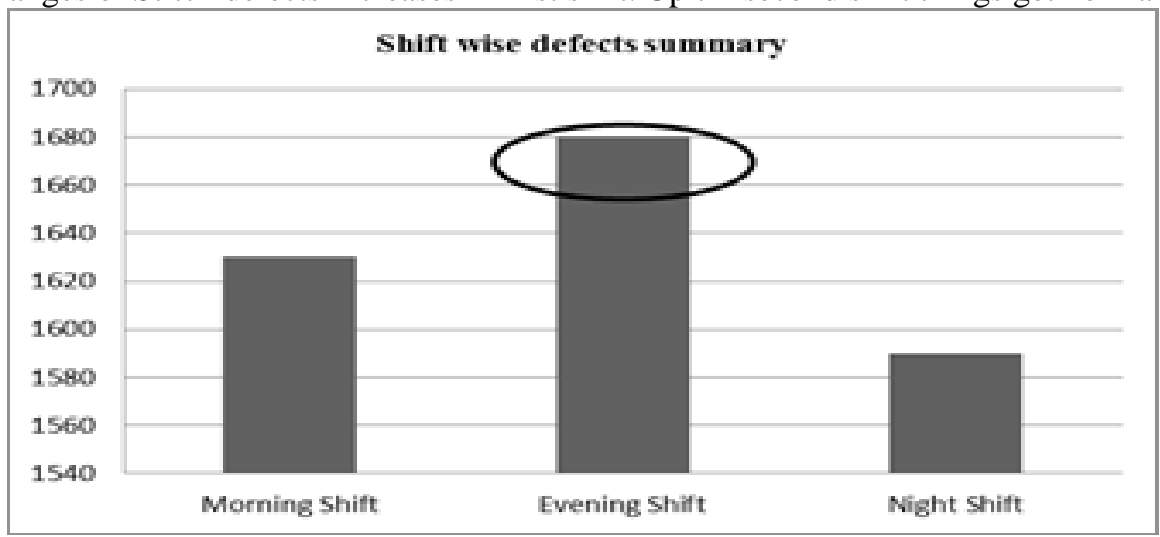

All overhauling is done mostly in morning shift by the maintenance team and restart the machine in evening shift.

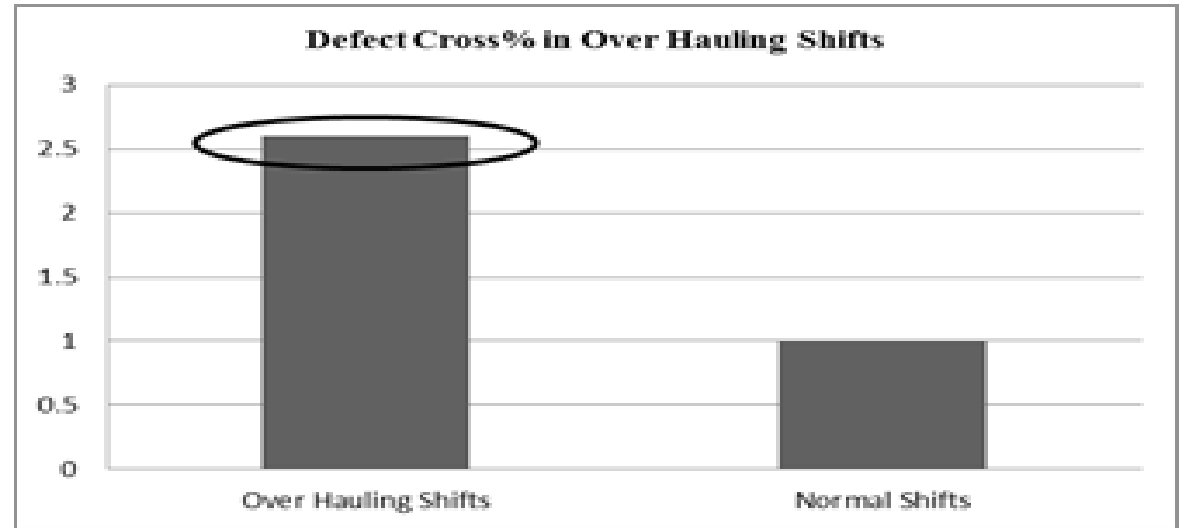

The same case product change case, mostly product change in morning and evening shift. Top management are absent in night shift and extra are avoided in night time. 


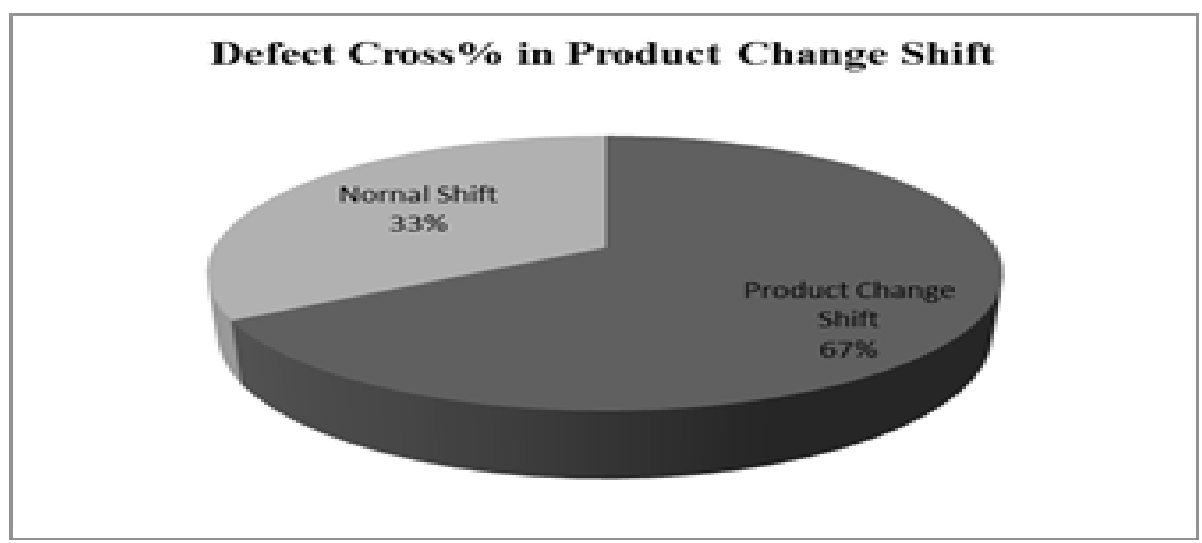

4.3.2 Effect of yarn type on Defect Stitch

Fig.13 Pie Chart of Shifts data

In the yarn type, there are three types of yarn in relation to its end use.

- Weaving Yarn

- Knitting Yarn

- Stretch Yarn (Lycra Yarn)

According to different type of yarn, it is clear that the weaving yarn has more defect Stitch and then comes Knitting and Lycra yarn.

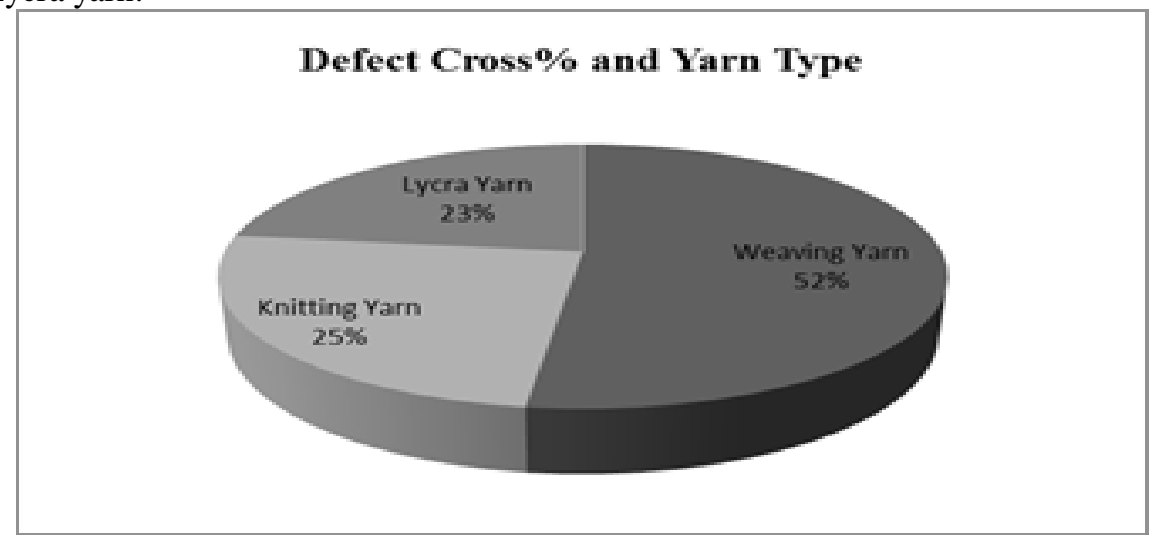

Fig.14. Defects in Yarn Type

Data shows that the fine count like 100s has high defects rate than the course count like 26s. As the count is going from fine to course, the defects rate goes down.

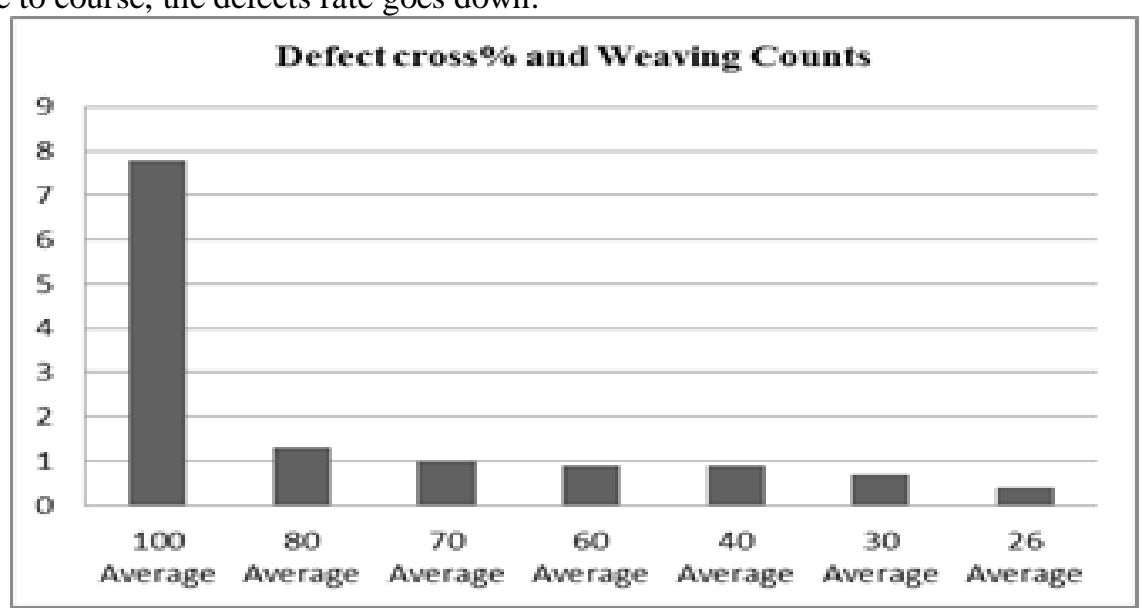

The same case in knitting yarn, knitting yarn of fine count has high defects rate than course counts and it is gradually decreases from 40 s to 26 s count. 


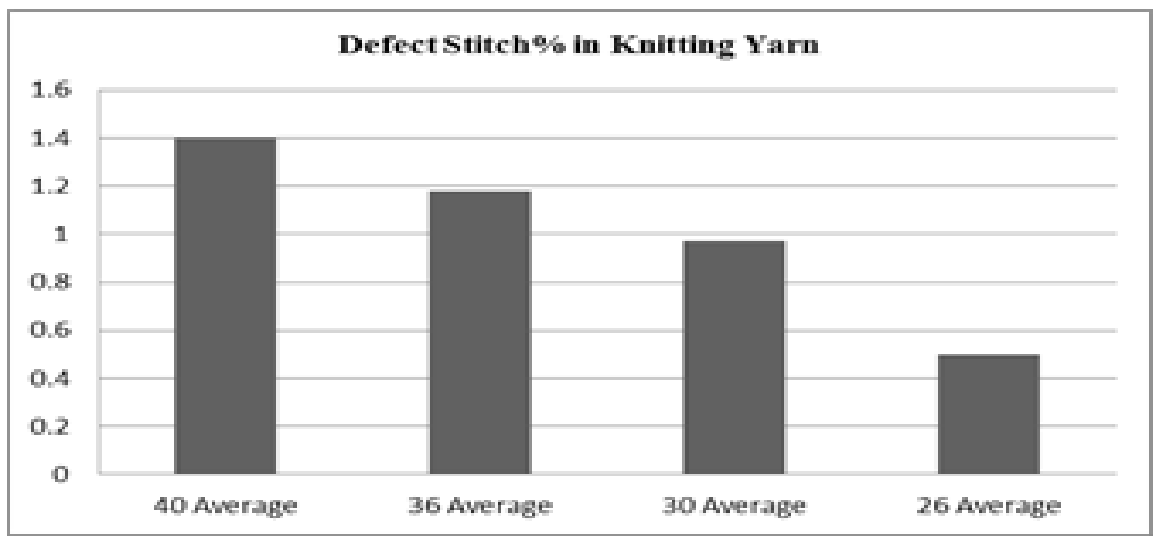

In lycra yarn, the same situation is also here but little bit difference because of lycra \%age of different yarn as per customer requirement.

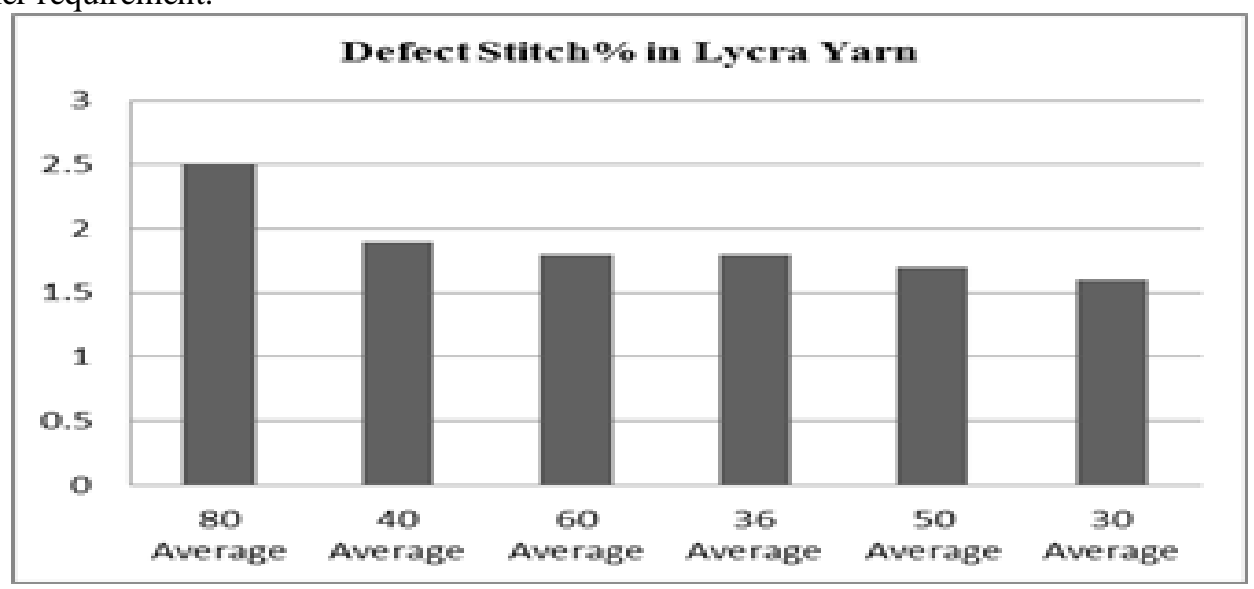

Fig.15. Defects in Yarn Count

In all types of yarn Weaving, Knitting and Lycra have more defects percentage in finer and lower as it goes towards course count. It is due to the finer count cone has more stay time on machine as compared to course counts. So opportunities of having stitch defects in finer counts cone is more as compared to courser counts cone. Whenever machine stopped for readjustment, overhauling and restarted it, then coming shift is critical to stitch defects.

\subsection{Improve Phase}

The improvement of process is calculated by the help of Design of Experiment. In order to improve the process, some settings are change which are the sever effect on the defects of final product.

In this normal plot, some significant factors are shown which causes major effects on the defects on the product in the winding process.

- Scan cuts

- Speed of winding machine

- Disk of machine

- Suction mouth gauge

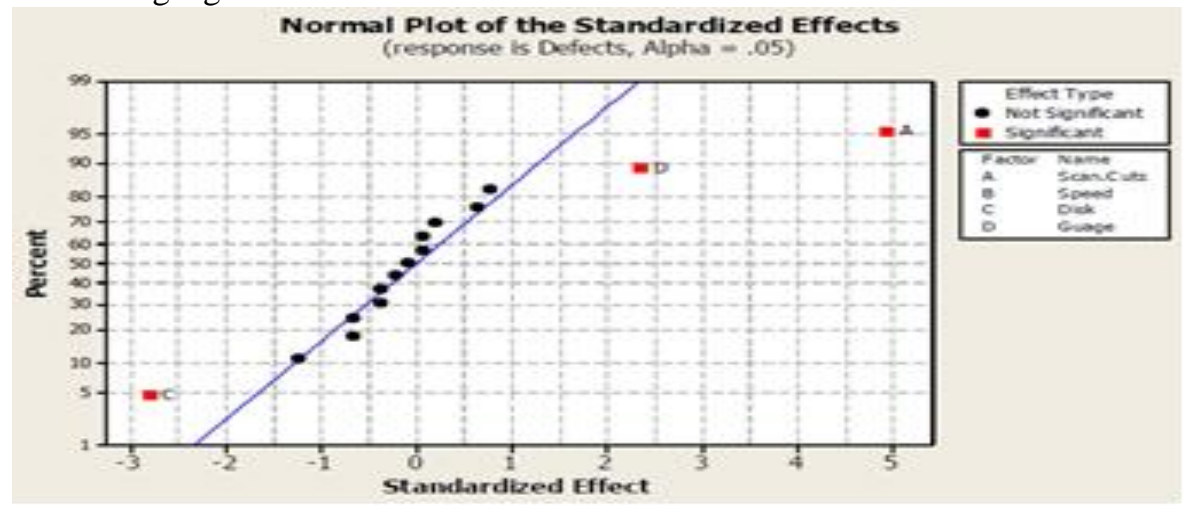

Fig.16. Normal plot of the standardized effects 


\subsubsection{Parameters}

Speed is already slow so no big influence on defect. Scan-Cuts and Disk life are most important factors. They need to be controlled to achieve optimum results best Scan-Cuts are below 40. Condition of Disk should be good always and the suction mouth gauge should be less than $6 \mathrm{~mm}$.

Table 4. Response Table for Defects

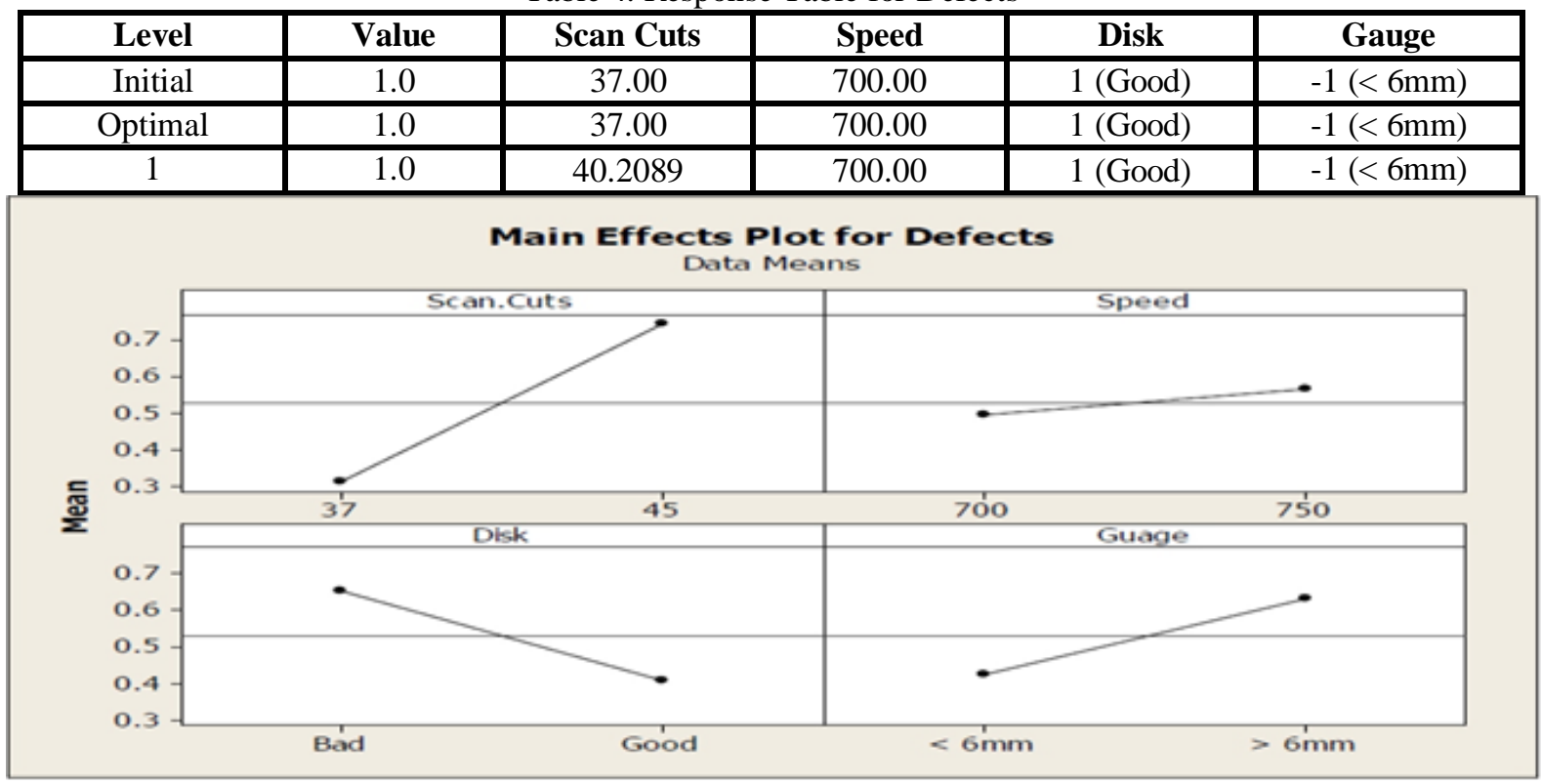

Fig.17. Normal plot of Design of Experiment

\subsection{Control Phase}

In control phase, the process will be check by applying the control charts whether it is control or not. Variation of whole process should be in control limits for control process.

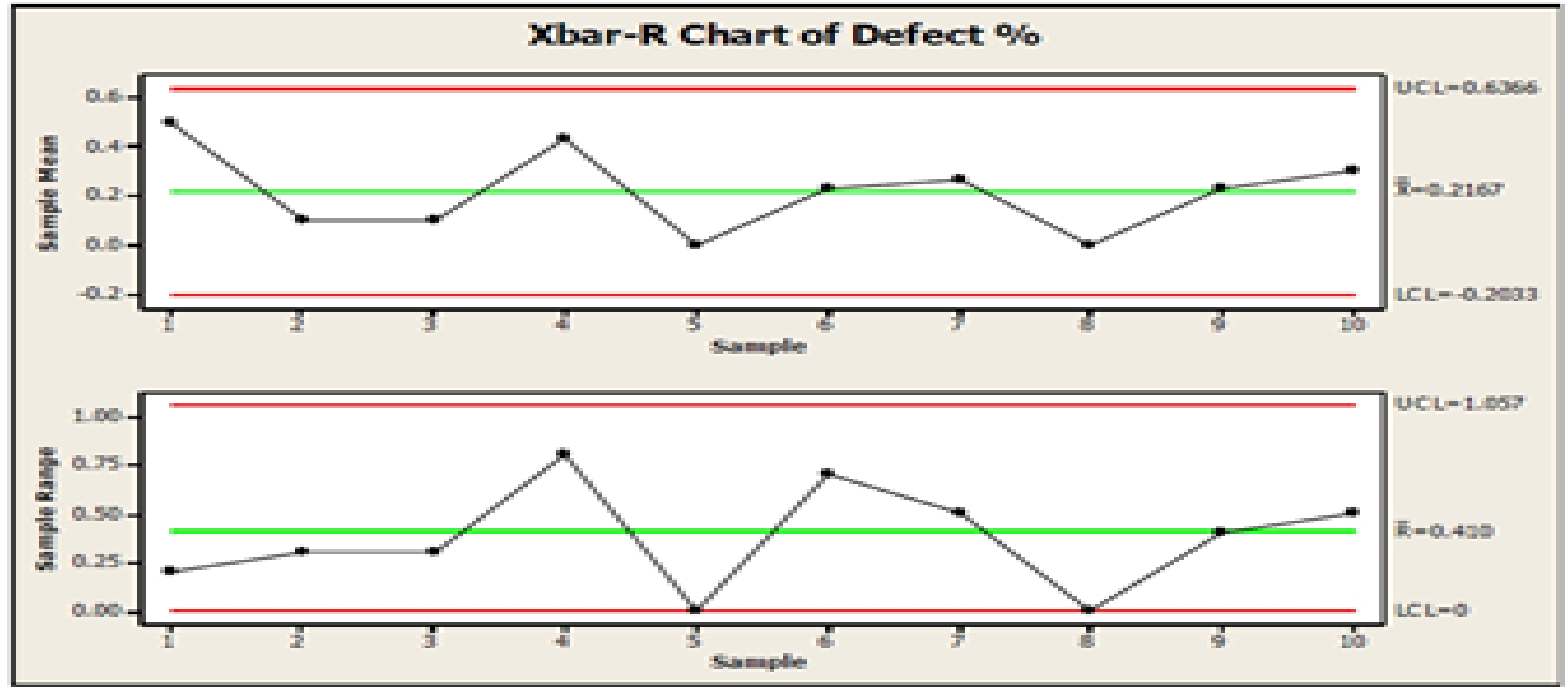

Fig.18. X bar- R chart

\subsubsection{Statistical process control}

Statistical process control is used to monitoring the consistency of process and makes the process is under control. Data of defects \%age shows that the process is under control and there is not any point in this graph which is out of control limits.

\subsubsection{Design the speed limits}

Speed of different yarn count on winding machine should be designed in different standard. The training of operators should also conduct for the understanding of speed limits of different product. 


\subsubsection{Inspection procedure}

Inspection procedure of maintenance department improved and checking of suction mouth gauge and tension disk on daily basis and make the part of daily checking sheet form. For the improvement of measurement system analysis following steps have been taken.

After categorization the stitch fault in the cone, it is included in the SOP as it was a great confusion among operators to detect a stitch cone fault. All operators were trained according to the new portion of SOP. After one month training of operators according to new portion of SOP, Measurement system analysis was conducted of attribute data.

Sample Selection-

Total Sample size $=50$ cones

Pass cones $=22$

Fail cones $=22$

Borderlines cones $=6$

No of Operators $=3$

No of trials/ operator $=2$

Overall appraiser \%age $=94 \%$

Overall attribute $\%$ age $=90 \%$

\section{CONCLUSION}

In this paper, we have achieved a lot of results regarding to process problems during manufacturing of yarn in different departments. The main thing in our paper is to reduce the defects rate and also reduce fault opportunities in the final yarn; we have worked in every department to reduce these opportunities and gave a solution in the form of preventive action. As in Six Sigma methodology, if we decrease the opportunities in the final product then we can increase the Sigma value which shows that the process improvement. We have also applied a basic tool of Six Sigma like DMAIC in our thesis in which highlighted the different phases of tool with respect to process behavior and importance in the manufacturing of yarn. Winding department where we have applied DMAIC tool is critical as compared to other departments in the process as it cause an increase defects rate percentage in the final product of yarn. In winding department, there is an Auto cone machine which winds the yarn on the cone and makes a final package for the end customers. It's better to implement DMAIC tool to eliminate or reduce the defects at the last section of the department. After this section, we can't improve the quality or reduce the defects in the final product.

\section{REFERENCES}

[1] O. Al-Araidah, A. Momani, M. Khasawneh, and M. Momani, "Lead-Time Reduction Utilizing Lean Tools Applied to Healthcare: The Inpatient Pharmacy at a Local Hospital,” Journal for Healthcare Quality, 2010, 32(1),pp. 59-66.

[2] M. Ali, "Six-sigma Design through Process Optimization using Robust Design Method," Master Thesis at Concordia University, Montreal, Canada, 2004.

[3] S. Bisgaard, and R. Does, "Quality Quandaries: Health Care Quality - Reducing the Length of Stay at a Hospital, Quality Engineering", 2009, 21, pp. 117-131.

[4] Y. H. Cheng, "The Improvement of Assembly Efficiency of Military Product by Six- Sigma," NCUT Thesis Archive, Taiwan, 2005 .

[5] M. E. Cournoyer, C. M. Renner, M. B. Lee, J. F. Kleinsteuber, C. M. Trujillo, E. W. Krieger, C. L. Kowalczyk, "Lean Six Sigma tools, Part III: Input metrics for a Glovebox Glove Integrity Program," Journal of Chemical Health and Safety, Article in press, 2010,pp. 412, 1-10.

[6] A. D. Desai, "Improving Customer Delivery Commitments the Six Sigma way: Case Study of an Indian Small Scale Industry," International Journal of Six Sigma and Competitive Advantage, 2006, 2(1), pp. 23-47.

[7] E. Dickson, S. Singh, D. Cheung, C. Wyatt, and A. Nugent, "Application of Lean Manufacturing Techniques in the Emergency Department," The Journal of Emergency Medicine, 2009, 37, pp. 177-182.

[8] J. Edgardo, V. Escalante, and A. Ricardo, "An application of Six Sigma methodology to the manufacture of coal products," World Class Applications of Six Sigma, 2006, 98-124.

[9] M. Hook, and L. Stehn, "Lean Principles in Industrialized Housing Production: the Need for a Cultural Change," Lean Construction Journal, 2008, pp.20-33.

[10] C. Huang, K. S. Chen, and T. Chang, "An application of DMADV Methodology for increasing the Yield Rate of Surveillance Cameras, Microelectronics Reliability," 2010, 50, pp. 266-272.

[11] R. Jain, and A. C. Lyons, "The Implementation of Lean Manufacturing in the UK Food and Drink Industry", International Journal of Services and Operations Management, 2009, pp. 5(4), 548-573.

[12] R. Krishna, G. S. Dangayach, J. Motwani and A. Y. Akbulut, "Implementation of Six Sigma in a Multinational Automotive Parts Manufacturer in India: a Case Study,” International Journal of Services and Operations Management, 2008, 4(2), $246-276$.

[13] Q. Lee,"The mental model: Lean Manufacturing Implementation”. Retrieved September 13, 2004, from http://www.strategosinc.com/lean_implemntation1.htm

[14] K. Linderman, R. Schroeder, Z. Srilata, and A. Choo "'Six Sigma: a Goal-Theoretic Perspective,” Journal of Operation Management, 2003,21,pp.193-203.

[15] D. Lioyd and J. Holesnback, "The Use of Six Sigma in Health Care Operations: Application and Opportunity," Academy of Health Care Management Journal, 2006, 2,pp. 41-49.

[16] N. Mandahawi, O. Al-Araidah, A. Boran, and M. Khasawneh, "Application of Lean Six Sigma Tools to Minimize Length of Stay for Ophthalmology Day Case Surgery,” International Journal of Six Sigma and Competitive Advantage, to appear, 2010. 
[17] N. Mandahawi, S. Al-Shihabi, A. A. Abdallah, and Y. M. Alfarah, "Reducing Waiting Time at an Emergency Department using Design for Six Sigma and Discreet Event Simulation," International Journal of Six Sigma and Competitive Advantage, 2010, 6(1/2), PP. 91-104.

[18] J. Mari, "Using Design for Six-Sigma to Design an Equipment Depot at a Hospital," Master Thesis at Binghamton University, State University of New York, USA, 2006.

[19] J. Miller, D. Ferrin, and J. Szymanski, "Simulating Six Sigma Improvement Ideas for a Hospital Emergency Department, Proceedings of the 2003 Winter Simulation Conference," 2003.

[20] S. S. Raab, C. Andrew-JaJa, J. Condel, and D. Dabbs, "Improving Papanicolaou Test Quality and Reducing Medical Errors by Using Toyota Production System Methods,” American Journal of Obstetrics and Gynecology, 2006, 194, pp.57-64.

[21] C. M. Roberts, "Six Sigma Signals," Credit Union Magazine 2004, 70 (1), pp.40-43.

[22] R. Rucker, "Citibank Increases Customer Loyalty with Defect-Free Processes, the Journal for Quality and Participation," 2000,23 (4), pp.32-36.

[23] M. Sampson, "Non Profit, Payload Process Improvement through Lean Management". Ph.D. Dissertation, University of Colorado.

[24] K. Schon, "Implementing Six Sigma in a Non-American Culture," International Journal of Six Sigma and Competitive Advantage, 2006, 2 (4), pp.404-428.

[25] M. Sokovic, D. Pavletic, and S. Fakin, “Application of Six Sigma Methodology for Process Design,” Journal of Materials Processing Technology, 2005, PP. 162-163, 777-783.

[26] C. Su and C. Chou, "A Systematic Methodology for the Creation of Six Sigma Projects: A Case Study of Semiconductor Foundry," Expert Systems with Applications, 2008, 34,pp. 2693-2703.

[27] J. P. Womack, "The Right Sequence for Implementing Lean", Lean Enterprise Institute, Accessed on February $13,2003$.

[28] H. Woodward, S. Scachitti, L. Mapa, C. Vanni, L. Brandford, and C. Cox, "Application of Lean Six Sigma Techniques to Optimize Hospital Laboratory Emergency Department Turnaround Time Across a Multi- hospital System,” Proceedings of the Spring, 2007, American Society for Engineering Education Illinois-Indiana Section Conference.

[29] Q. Yu, and K. Yang, "Hospital Registration Waiting Time Reduction through Process Redesign," International Journal of Six Sigma and Competitive Advantage, 2008, 4(3),pp. 240-253.

[30] Bourton Hall, Rugby, Warwickshire CV23 9SD, "The Six Sigma Group” 2010, Retrieved July 20.

[31] http://www.sixsigmagroup.co.uk/introduction/whatissixsigma.aspx

[32] Six Sigma. (n.d).Quality Resources for Achieving Six Sigma Results. Retrieved July 20, 2010 from isixsigma.com http://www.isixsigma.com/index.php?option.com

[33] F. M. Ahmad, \& A. Khan, "Internship Report on Gull Ahmad Textile Mill Report," Retrieved July 22, 2010, from Gul Ahmad Textile Mill: http://www.docstoc.com/docs/16936290/Spinning-report

[34] T. Vijykumar, “Report on experience with the Rieter C 60 CARD. Link, ,2007, 19 (51),pp. 3-6.

[35] Angelfire. (n.d.). Carding. Retrieved June 18, 2010, from Angelfire:http://www.angelfire.com/jazz/pakspinning/CARDING.htm

[36] Angelfire. (n.d.). Draw Frame. Retrieved 2010, June

Angelfire:http://www.angelfire.com/jazz/pakspinning/DRAWING\%20PROCESS.htm
[37] S. Bashir, (2010, June $\quad$ 6). Blow Room. Retrieved June 2010, from Angelfire: http://www.angelfire.com/jazz/pakspinning/BLOWROOM.htm
Yarn Spinning Technology. (n.d.). Combed Yarn for Knittinig. Retrieved June 10, 2010, from Yarn Spinning Technology: http://textiletechnology.bravehost.com/spinning/yarnquality.htm

[39] Textile Spinning. (n.d.). Defects in Blow room and causes. Retrieved June 15, 2010, from Textile Spinning: http://www.textilespinning.co.cc/modernblowroom/Defects_in_Blow_Room.htm

[40] Purushothama, B. (n.d.). MODERN AUTO LEVELLER DRAW FRAMES. Retrieved July 05, 2010, from fibashion.com: articles.fibashion.com/extraimage/article/document/Article_275.docx

[41] Textile Technology Spinning. (n.d.). PROCESS PARAMETERS IN DRAW FRAME. Retrieved July 02, 2010, from Textile Technology Spinning: http://www.textiletechnology.co.cc/spinning/processpardrawing.htm

[42] Textile spinning. (n.d.). Defects in Card Sliver. Retrieved 2010, from Textile spinning:http://www.textilespinning.co.cc/carding/DEFECTS_IN_CARD_SLIVER.htm

[43] Angelfirre. (n.d.). Comber. Retrieved Angelfire.com:http://www.angelfire.com/jazz/pakspinning/COMBING\%20PROCESS.htm

[44] Angelfire. (n.d.). Roving Frame. Retrieved angelfire.com:http://www.angelfire.com/jazz/pakspinning/roving_frame.htm

[45] Textile Technology Spinning. (n.d.). Roving Frame. Retrieved July 18, 2010, from Textile Technology Spinning: http://www.textiletechnology.co.cc/spinning/ROVINGFRAME.htm

[46] Textile Technology Spinning. (n.d.). Winding Spinning. Retrieved July 20, 2010, from Textile Technology Spinning: http://textiletechnology.blogspot.com/2008/04/winding-spinning.html

[47] Six Sigma. (n.d).Quality Resources for Achieving Six Sigma Results. Retrieved July 20, 2010 from isixsigma.com http://www.isixsigma.com/index.php?option=com

[48] The Six Sigma Group. Bourton Hall, Rugby, Warwickshire CV23 9SD. Retrieved July 20,2010http://www.sixsigmagroup.co.uk/introduction/whatissixsigma.aspx

[49] Six $\quad$ Sigma.(n.d). $\quad$ Six $\quad$ Sigma $\quad$ Overview. $\quad$ Retrieved $\quad$ july $\quad 01, \quad 2010 . \quad$ From thequalityportal.comhttp://www.thequalityportal.com/q_6sigma.htm

[50] Pyzdek Thomas, "The Six Sigma handbook; a complete guide for green belts, black belts, and managers at all levels" (Published by: New York McGraw-Hill, c2003) Chapter 1 Pages 4-5.

[51] Tennant Geoff, "SIX SIGMA: SPC and TQM in Manufacturing and Services" Gower Publishing, Ltd. (2001) Chapter 1 “The development of quality" Pages 1-3

[52] Educational assessment: Interpreting test scores, Reliability and validity. Retrieved 15 july, 2010 Online available: http://course1.winona.edu/lgray/el626/MandEtext3.html

[53] Peter R.Loard."The Economies, Science and Technology of Yarn Production" The textile institute 10 Black friar Manchester, England 1981, Chap.12 Pages. 149-171 